\title{
Exploration on the Reform of College Sports Management under the Background of Sunshine Sports
}

\author{
Xuehua Li \\ Xi'an International University, Xi'an 710077, China
}

Keywords: sunshine sports; University education; Management reform.

\begin{abstract}
With the slogan "sunshine sports", the reform of physical education advocated conveniently, especially on the management problems. We hope to find a more powerful teaching mode to meet new requirements of education concept which advocate by the government based on the present state of our country. This paper analyzes the problems related to the reform of college sports management under the background of the sunshine sports. The author analyzes the condition of the physical education teaching in colleges and universities, discusses the reform of the practical countermeasures. The purpose is to improve the efficiency of national colleges and universities sports management steadily.
\end{abstract}

\section{Introduction}

Many colleges and universities pay close attention to the concept of "sunshine sports" and carry out in-depth research on it. Most of them have apply this concept to the management of extracurricular sports activities. "Sunshine sports" is a slogan that guides the reform of physical education. The implementation of this concept is conducive to students' physical and mental health and encourages them to exercise actively so they can work and live in a healthier state of mind and body. Education in colleges and universities is related to the future development of the country. Therefore, practicing the concept of "sunshine sports" have a direct impact on the sustainable development of the national future.

\section{The Basic Connotation and Practical Significance of "Sunshine Sports"}

\subsection{Basic Connotation.}

On December 20, 2006, we put forward "sunshine sports". The ministry of education and the general administration of sport of China promulgated the following decision. Since 2007, the national academies should actively participate in the sunshine sports. "Sunshine sports" means to encourage students to get out of the regular classroom and take active part in the exercise under the sun. This is conducive to enhancing the awareness of sports fitness. It meets the needs of teenagers that grow freely in the natural environment and has a remarkable effect on the physical and health level of the students.

\subsection{Practical Significance.}

The healthy growth of young people is the hope of the nation's future. The health of young people can reveal the national health quality, which is related to the national competitiveness. According to the relevant survey results, in the youth group in China, the deterioration of physical fitness is very serious. This has seriously affected the image of the country's healthy power, so we should pay attention to such issues. The development of "sunshine sports" is the key to sustainable development, and it also actively implements the concept of harmonious education. To ensure the smooth development of the country, we need to pay attention to the details and ensure the steady progress of the goal of healthy development.

A. Actively exercise students' physical and mental quality.

Carrying out sunshine sports, can actively promote students' physical and mental quality. In the process of participating in sports, students can improve their physical and mental health [2]. At the 
same time, sunshine sports also exercise the students' communicative ability, it builds a more harmonious way of communication, and creates a fair environment. This will enable students to actively face the society, improve their self-worth and realize their true dreams.

B. Develop a more resilient character and quality.

Sunshine sports policy can help students build up their self-confidence and cultivate their strong, brave and tenacious character. At the same time, the sunshine sports policy can make students to go beyond themselves in action and shoulder their own responsibilities and obligations, it can help students to establish a scientific competition consciousness, develop healthy living habits and adapt to the changing society.

C. Promote the industrialization of college sports.

Sunshine sports can have a direct impact on education of college sports, to facilitate its trend towards industrialization and achieve a more long-term goal [3]. Sunshine sports can arouse people's awareness of participating in sports and make buying sports goods a trend. Colleges and universities can use this opportunity to contact sports industry resumes, to realize the sports venues, equipment "rent", "borrow". Therefore, based on the actual needs of physical exercise, a certain proportion of economic income is obtained, and the production and management of the sports industry in colleges and universities tend to be socialized.

\section{Basic Overview of Sports Management in Colleges and Universities}

In college education, sports are indispensable. The development of sports work involves many aspects, such as teaching method, teaching structure and purpose, way, etc. In carrying out teaching activities, the teaching objectives should be carried through the whole teaching process. The key to cultivate the psychological quality is good, the students with healthy physique are the basic conditions of the work. The importance of physical education in colleges and universities can be expected. In every detail, it is necessary to carry out supervision and guidance, and not neglect the exercise of students' physique. In the sports management work at the same time, also should fully consider the actual situation of the students, the careful analysis of the demand at the same time, to ensure that the selected teaching methods and organizational forms of setting reasonable science, convenient to be able to realize the teaching goal. When students have a healthy body, they can establish the basic beliefs of happiness education and lifelong sports.

\section{The Present Situation of College Sports Management Reform Under the Background of Sunshine Sports.}

\subsection{Students Lack the Awareness of Lifelong Sports.}

Today, the social economy is developing steadily. The social demand for talent shows a gradual upward trend. To better adapt to the development needs of the society, we should adopt a diversified way to cultivate talents. Modern people have a wealth of theoretical knowledge but failed to set up the consciousness of lifelong sports, on the psychological quality and physical health problems such as not attention, this is one of the problems in the current college sports management reform.

\subsection{The Configuration of Education Resources Lacks Rationality.}

As an important institution that disseminates the idea of sunshine sports, colleges and universities should assume their own responsibilities. Colleges and universities should play their due role so that students can have a relatively good sports space. But the current actual situation is not very desirable, more problems, more physical education resources in the configuration as to maintain the basis of the quality of education, teachers will be crucial influence on the students [4]. Basic configuration irrationality makes the students unable to better meet the needs of the development of society, together with the number of college teachers and students is various, this mismatch sex makes it hard for colleges and universities sports teaching requirements are met, and even the students interested in sports can develop smoothly. 


\subsection{The Teaching Model Lacks Innovative Ideas.}

In education, the number of physical education courses is limited, so that students can participate in the exercise less and less, so the physical education effect is not obvious. The existence of this situation is very common, which makes the overall sports level of some colleges and universities difficult to rise to the new level, which is not conducive to the birth of high-quality teaching results.

\subsection{Lack of Practicality in Sports Teaching Contents.}

At present, many colleges and universities sports teaching still at the primary stage, only to teaching mode be established, but still influenced by the Soviet Union, pattern is always taken to competitive sports to do, so that always leads the development of national physical education teaching material system, pay attention to sports skills and knowledge to teach, pay attention to the quality of the human body to ascend, deviating from the sports teaching goal and development requirements.

\section{Measures for the Reform of College Sports Management Under the Background of Sunshine Sports.}

\subsection{Promote the value of talent cultivation in physical education.}

With the development of sunshine sports, college sports management reform is also on the agenda. University party and administrative departments need to focus on the actual effect of physical education teaching, the curriculum arrangement in place at the same time, establish and improve the college sports curriculum system, pushing the activities carried out can be effective system support, encourage activities in the process of conducting can date normalization and standardization.

\subsection{Constructing a Relatively Perfect System of Teaching Principles.}

Teaching principle refers to the principle of teaching work according to the basic goal of education. This is the most objective reflection of the teaching work, it is the guarantee that the teaching process can proceed smoothly and obtain the high-quality result. At present, the goal of physical education in colleges and universities is to positively strengthen students' physique, ensure their physical and psychological development, and lay a solid foundation for lifelong sports and sports. Under the background of sunshine sports, sports teaching in colleges and universities must establish a more perfect system of teaching principle, to maintain the activities carried out more in place, meet the criteria of unity education, to promote two-way between teachers and students' enthusiasm was improved.

\subsection{Strengthen the Construction of Physical Education Courses.}

Under the background of sunshine sports, college sports should promote the reform of teaching content carefully, combined with a curriculum goal, the universities sports teaching content must be comprehensive analysis of the basic benefit of college sports soon and long-term, such ability assure you of the construction of the index trend. Should from the perspective of students and the society, to analyzes the actual demand of the health, select targeted rich curriculum, should be closely related to the pulse of the fashion sports, will introduce a rich variety of sports and college sports, let the students according to their own interest to choose project. Should also be on the development of physical education curriculum Angle analysis, timely add courses, encourage students to broaden the knowledge, to strengthen the skills at the same time, steadily improving its comprehensive quality [5]. According to the adjustment and change of the course content, the author makes reasonable physical education materials to ensure the teaching quality and the improvement of the effect steadily.

\subsection{Steady Implementation of the Sports Club System.}

For college students, physical education is a relaxing course, so they are more willing to be exposed to a relaxed and lively atmosphere. To make physical education seem to be more flexible, can according to the actual need of colleges and universities, the choice of concrete project builds up the club, this is one of the forms of launching sunshine sports movement, mainly in the form of club teaching, which is in the same class, the appropriate open a rich variety of projects, project independent of a club, students can choose according to their own actual situation, whether it is a time or in content are flexible. Using such teaching form, can timely make up the deficiency during a single 
sports teaching in, whether it's limitations or monotonicity, can timely improvement, steadily enhance the enthusiasm of the students participate in sports, help it to achieve comprehensive development.

\subsection{Pay Attention to the Dissemination of Theoretical Knowledge of Sports and Health}

The dissemination of knowledge of sports and health theory is very important, which is an important condition for students to participate in sports and is a necessary way to guide their practice [6]. In physical education teaching in colleges and universities, it is necessary to timely reasonable theory of sports and health knowledge, strengthen the propaganda on the concept of "health first", make the students set up the consciousness of lifelong sports, in mastering the science fitness method, to form the habit of good solid foundation. The knowledge of sports and health basic theory covers more abundant contents, such as the purpose of education, the task and the effect of strengthening constitution.

\subsection{Pay Attention to the Construction of University Sports Teaching Staff}

Teachers as the guide in teaching, students can achieve good sports results depend on the overall situation of teachers. Therefore, when conducting the sunlight sports, colleges and universities need to focus on the construction of teachers' team, change ideas, encourage teachers to take reasonable teaching methods and teaching modes, fully combined with the actual situation, to develop a reasonable and scientific teaching target, using scientific means, mobilize the students' interest in sport, to gradually form the consciousness of self-exercise. According to the actual situation of colleges and universities, a scientific and effective comprehensive evaluation system is formulated, and various methods are used to steadily improve the quality and quality of physical education teachers.

\subsection{Improve the Evaluation and Evaluation Mechanism of Sports Achievements}

To better test the achievements of students participating in sunshine sports, we can gradually improve and improve the evaluation mechanism of sports achievement assessment. The evaluation of physical education is based on the basic goal and standard of physical education, and the scientific decision is made on the quality of physical education. In the traditional evaluation model, the more is adopted unified standards set by the school, so only to horizontal evaluation of students, reflects the summative evaluation characteristics, cannot accurately reflect students' actual situation, it is difficult to meet the basic requirement of knowledge economy era. Asked many colleges formulated in accordance with the unified state of sunshine sports movement indicators, situation analysis, the movement of the students on their performance appraisal result and daily comprehensive to understand, accurate analysis of the comprehensive situation of students. By this way, can actively mobilize the students' learning enthusiasm, encourage the sport has enough interest, at the same time of strengthening the physique, supervise and urge its develop good exercise consciousness, guarantee the belief of lifelong sports.

\section{Conclusion}

Influenced by the concept of sunshine sports, we are very concerned about the reform of sports management in colleges and universities. Many students, for their own reasons, do not understand the concept of lifelong sports, so that they cannot actively cooperate with the activities of university sports management. In addition, in the reform of college sports management, we should pay attention to other problems and take targeted improvement measures. Sunshine sports are the concrete action of strictly implementing the party education policy, adhering to the guiding ideology of "health first", and the concept of proper communication of sports for hundreds of millions of students. This slogan advocacy and action in the country at the present stage mainly for the "heavy brain light body" of the existence of education concept proposed, combining the teenagers in physical health problems, to find the corresponding improvement measures, the purpose is to realize the mass movement, at the same time it can encourage teenager to build the brief of lifetime sport. 


\section{References}

[1]. Wei Shaohua, Huang Lu. The effective analysis of college sports management under the background of "sunshine sports" [J]. Macroeconomic management,2017(S1):151-152.

[2]. Lei Zhen, Wu Yong, Zhang Qian. Analysis and Suggestions on the development of sunshine sports in college sports clubs [J]. Journal of Anhui normal university (natural science edition),2016,39(01):89-92.

[3]. Wu Runping. The reform status and model construction of college physical education under the background of sunshine sports. Journal of Guangzhou institute of physical education,2015,35(05):100-103.

[4]. Wang Man, construction of innovative system of physical education teaching mode for universities facing sunshine sports [J]. Journal of southwest normal university (natural science edition),2014,39(09):185-188.

[5]. Wang Shunxia. The current situation and countermeasures of the operation mode of sports associations in Shanghai universities under the perspective of sunshine sports [J]. Shandong sports science and technology,2013,35(03):92-95.

[6]. Wu Xuimin. Research on the status quo and countermeasures of physical dance teaching in colleges and universities in Shandong province under the background of "sunshine sports" [J]. Journal of Shandong institute of physical education,2011,27(03):86-90.

[7]. Yang Qingci, Yi Changjiang. Study on the reform of college physical education curriculum under the background of "sunshine sports" [J]. Journal of Baoshan college,2010,29(02):97-100. 